\title{
Modulation of fluid absorption and the secretory response of rat jejunum to cholera toxin by dietary fat
}

\author{
F A Sagher, J A Dodge, R Moore, C McMaster, G McCaughey
}

\begin{abstract}
To study the effects of dietary fat on jejunal water and ion absorption and on cholera toxininduced secretion, 3 week old Sprague Dawley rats were fed isocaloric diets. Forty per cent of the total calories were given as fat, as butter (high saturated fat), olive oil (high monounsaturated fat), or corn oil (high polyunsaturated fat), with one group on low fat ( $10 \%$ of calories) standard laboratory diet as controls. During in vivo jejunal perfusion studies we found that (i) a polyunsaturated fat (corn oil) supplemented diet improves jejunal absorption of water and electrolytes and these changes are independent of the observed concentrations of luminal prostaglandins; (ii) high dietary fat appreciably reduced the secretory response to cholera toxin, probably without fundamentally changing the mechanism by which cholera toxin induces secretion. We conclude that dietary fat composition altered the permeability and transport characteristics of the small intestine. This observation might have relevance to some human diarrhoeal disorders.
\end{abstract}

Interest in dietary modification of intestinal ion transport and eicosanoid synthesis has arisen both as an alternative approach to studying their physiological importance and for possible therapeutic value. Evidence is gradually accumulating for a protective effect of dietary fat in diarrhoeal disorders. Epidemiological studies suggest a possible relation between low milk fat intake in children and an increased incidence of gastrointestinal illnesses, especially diarrhoea. Careful analysis failed to explain the association and it was concluded that there may be a nonimmunoglobulin factor in milk fat which prevents diarrhoeal illness. ${ }^{1}$

In a clinical study children with chronic nonspecific diarrhoea who had no evidence of malabsorption were found to be taking low fat diets, and they responded well to polyunsaturated fat supplementation. ${ }^{23}$ In the laboratory fractionation of human milk by ammonium sulphate precipitation and column chromatography yields a non-immunoglobulin fraction which has been shown to protect rabbits against enterotoxininduced intestinal fluid secretion in vitro. Preliminary experiments showed that the inhibitory activity was extracted by chloroform and methanol, which suggests the involvement of lipid. ${ }^{+}$A glycoprotein or a glycolipid compound in the non-immunoglobulin fraction of human milk has recently been shown to inhibit the adherence of certain enterotoxigenic Escherichia coli strains to guinea pig intestinal tract. ${ }^{5}$

The present study was designed to investigate further the relations between diet and function and to explore the possible protective value of different types of dietary fat in a rat model of secretory diarrhoea.

\section{Methods}

PREPARATION OF ANIMALS AND DIETS

Three week old male Sprague Dawley rats were fed one of three synthetic diets. The diets contained $20 \%$ fat, which provided $40 \%$ of the total calories, as butter, olive oil, or corn oil. The diets were isocaloric and nutritionally adequate, providing all known essential requirements (Special Diet Service, Essex, England). A control group was maintained on a standard low fat (10\% of calories) diet (Beta-Laboratory Diets Witham) (Table I). The fatty acid composition of the diets is shown in Table II. To reduce coprophagy animals were housed individually with alternate 12 hours of light and dark, in cages with a mesh wire bottom, and their intake was calculated daily.

The diet high in saturated fatty acids (butter) provided $24.6 \%$ of the total fatty acids and $9 \cdot 8 \%$ of the total calories (\% wt/wt) as oleic acid, and approximately $2 \cdot 5 \%$ of the total fatty acids and $0.95 \%$ of the total calories as linoleic acid, whereas only approximately $0.6 \%$ of the total fatty acids and $0 \cdot 2 \%$ of the total calories were provided as $\alpha$ linolenic acid, with a w6/w3 ratio of $4 \cdot 75$.

The diet high in polyunsaturated fatty acids (corn oil) provided $29.78 \%$ of the total fatty acids and $11.9 \%$ of the total calories as oleic acid, approximately $58 \%$ of the total fatty acids and $23 \cdot 2 \%$ of the total calories as linoleic acid, and only approximately $0.2 \%$ of the total fatty acids and $0.8 \%$ of the total calories were provided as $\alpha$ linolenic acid, with a w6/w3 ratio of 29 .

The diet high in monounsaturated fatty acids (olive oil) provided $79.4 \%$ of the total fatty acids and $31.7 \%$ of the total calories as oleic acid, approximately $7 \%$ of the total fatty acids and $2 \cdot 8 \%$ of the total calories as linoleic acid, but only approximately $1 \%$ of the total fatty acids and

TABLE I The basic diet per $1 \mathrm{~kg}$ of complete diet

\begin{tabular}{llc}
\hline & Synthetic $(g)$ & Control \\
\hline Fat $^{\star}$ & 200 & 35 \\
Protein (casein) vitamin free & 200 & 173 \\
Carbohydrate: & 250 & 549 \\
$\quad$ Corn starch & 250 & \\
$\quad$ Sucrose & 20 & $11 \cdot 3$ \\
Vitamin mix & 40 & $43 \cdot 2$ \\
Salt mix & 40 & 31 \\
Fibre (non-nutritive) & & \\
\hline
\end{tabular}

^Dietary fat as high monounsaturated (olive oil), or high saturated (butter), or high polyunsaturated (corn oil). 
TABLE II Fatty acid profile of diets ${ }^{\star}$

\begin{tabular}{|c|c|c|c|c|}
\hline \multicolumn{4}{|l|}{$20 \%$ fat } & \multirow{2}{*}{$\begin{array}{l}\text { Standard diet } \\
3 \cdot 5 \% \text { fat } \\
(\% \text { wt })\end{array}$} \\
\hline Fatty acid & $\begin{array}{l}\text { Olive oil }(H M U) \\
(\% w t)\end{array}$ & $\begin{array}{l}\text { Butter (HS) } \\
(\% w t)\end{array}$ & $\begin{array}{l}\text { Corn oil }(H P U) \\
(\% \text { wt })\end{array}$ & \\
\hline $6: 0$ & - & $0 \cdot 28$ & - & - \\
\hline $8: 0$ & - & 0.86 & - & - \\
\hline $10: 0$ & - & $2 \cdot 82$ & - & - \\
\hline $12: 0$ & - & $2 \cdot 89$ & - & - \\
\hline $14: 0$ & $0 \cdot 12$ & $17 \cdot 02$ & $0 \cdot 26$ & 0.57 \\
\hline $14: 1$ & - & $1 \cdot 32$ & - & - \\
\hline $15: 0$ & - & $1 \cdot 21$ & - & - \\
\hline $16: 0$ & $9 \cdot 22$ & $31 \cdot 25$ & $8 \cdot 46$ & $13 \cdot 87$ \\
\hline $16: 1$ & - & 1.72 & - & - \\
\hline $17: 0$ & - & 0.86 & - & - \\
\hline 18:0 & 2.94 & $10 \cdot 38$ & 1.76 & $2 \cdot 15$ \\
\hline $18: 1$ & $79 \cdot 36$ & $24 \cdot 58$ & 29.78 & 22.51 \\
\hline $18: 2$ w6 & 6.99 & $2 \cdot 39$ & $57 \cdot 78$ & $54 \cdot 13$ \\
\hline $18: 3$ w3 & 0.89 & 0.58 & 1.97 & 6.28 \\
\hline $20: 1$ & - & - & - & - \\
\hline Others & - & $1 \cdot 84$ & - & - \\
\hline Saturated & $12 \cdot 28$ & $67 \cdot 57$ & $10 \cdot 48$ & $16 \cdot 59$ \\
\hline Monounsaturated & $80 \cdot 16$ & $27 \cdot 62$ & $29 \cdot 78$ & 23.01 \\
\hline Polyunsaturated & $7 \cdot 88$ & $2 \cdot 97$ & $59 \cdot 75$ & $60 \cdot 41$ \\
\hline
\end{tabular}

^Diets analysed by Department of Food Biochemistry, Faculty of Agriculture, Queen's University of

HMU = high monounsaturated; HS=high saturated; HPU = high polyunsaturated.

$0.4 \%$ of the total calories were provided as $\alpha$ linolenic acid, with a w6/w3 ratio of 7 .

STEADY STATE JEJUNAL PERFUSION STUDIES

The non-stimulated perfusions were performed on adult male Sprague Dawley rats after an overnight fast (18-20 hours) during which water only was allowed ad libitum. Before laparotomy, anaesthesia was induced with intraperitoneal sodium pentobarbitone $(60 \mathrm{mg} / \mathrm{kg})$ and maintained when necessary with intramuscular doses of $0.3 \mathrm{mg} .{ }^{6}$ Rectal temperature was maintained throughout the experiment at $37(1)^{\circ} \mathrm{C}$ (mean (SEM)) by an electrically heated pad. The perfusion studies were essentially as described by Sladen and Harries ${ }^{7}$ with some modification as follows.

The abdomen was opened with a midline incision and about $20 \mathrm{~cm}$ length of jejunum from the duodenojejunal junction was prepared. The inlet catheter (polyvinyl tubing bore $0.63 \mathrm{~mm}$, diameter $1.4 \mathrm{~mm}$ ) and the outlet catheter (polyvinyl tubing bore $2 \mathrm{~mm}$, diameter $3 \mathrm{~mm}$ ) were inserted into the gut and tied firmly in position with silk ligature. Faecal material, if present, was removed from the loop by washing with the perfusate at $37^{\circ} \mathrm{C}$, then the loop was returned to the abdominal cavity.

The final perfusate contained (mmol/l): $\mathrm{Na}^{+}$ $155, \mathrm{~K}^{+} 4, \mathrm{Cl}^{-} 130$, total $\mathrm{CO}_{2} 21$, glucose $1 \cdot 6$, polyethylene glycol (PEG 4000) $3 \mathrm{~g} / \mathrm{l}$ as nonabsorbable marker with $5 \mu \mathrm{Ci} / 1$ of ${ }^{14} \mathrm{C}$ PEG. $\mathrm{pH}$ was adjusted to $7 \cdot 0$ and the osmolality of the solution adjusted to (mean (SEM)) $299(1.5)$ $\mathrm{mOsmol} / \mathrm{kg}$.

TABLE III The characteristics of animal growth

\begin{tabular}{|c|c|c|c|}
\hline Diet & $\begin{array}{l}\text { Weight at age } \\
20 \text { days }(\mathrm{g})\end{array}$ & $\begin{array}{l}\text { Weight at end of } \\
\text { experiment }(g)\end{array}$ & $\begin{array}{l}\text { Duration of } \\
\text { feeding (weeks) }\end{array}$ \\
\hline $\begin{array}{l}\text { Control }(n=14) \\
\text { Butter }(n=14) \\
\text { Olive oil }(n=19) \\
\text { Corn oil }(n=12)\end{array}$ & $\begin{array}{l}42 \cdot 1(2 \cdot 6) \\
40 \cdot 5(0 \cdot 8) \mathrm{NS} \\
38 \cdot 3(1 \cdot 3) \mathrm{NS} \\
40 \cdot 4(1 \cdot 7) \mathrm{NS}\end{array}$ & $\begin{array}{l}277 \cdot 2(21 \cdot 8) \\
270(17 \cdot 9) \mathrm{NS} \\
289 \cdot 3(18 \cdot 7) \mathrm{NS} \\
309(21 \cdot 2) \mathrm{NS}\end{array}$ & $\begin{array}{l}8 \cdot 4(0.5) \\
8 \cdot 2(0.5) \mathrm{NS} \\
8 \cdot 4(0.5) \mathrm{NS} \\
8 \cdot 6(1.08) \mathrm{NS}\end{array}$ \\
\hline
\end{tabular}

The solution was perfused in a single pass perfusion at a rate of $0.45 \mathrm{ml} / \mathrm{min}$ using a Harvard infusion pump. The solution was warmed and kept warm through coils of polyvinyl tubing placed into a water bath and the water bath temperature adjusted so that the temperature of the perfusate was $35(1)^{\circ} \mathrm{C}$ as it entered the intestine. After 30 minutes, which was sufficient to reach an equilibrium state in preliminary experiments using recovery of ${ }^{14} \mathrm{C}$ PEG as an index, three consecutive 10 minute collections of effluent were obtained. Each collection was analysed for net absorption and net secretion of water and solutes using the standard formula. ${ }^{8}$

The results were expressed in $\mu \mathrm{l}$ or $\mu \mathrm{mol} / \mathrm{min}$ per $g$ wet weight. Negative results indicate net secretion. Positive results indicate net absorption.

In the cholera toxin experiment perfusions were performed on adult female Sprague Dawley rats. These were sibs of the male rats used in the steady state studies. Each group of experiments was performed on single sex animals to eliminate possible sex related variations in absorption, and in preliminary studies females had been shown to tolerate prolonged anaesthesia better than males. A blind loop was initially constructed from the jejunum as described by Harries and Sladen. ${ }^{7}$ Faecal material, if present, was removed from the loop by washing with the perfusate at $37^{\circ} \mathrm{C}$. $75 \mu \mathrm{g}$ of cholera toxin dissolved in $0.75 \mathrm{ml}$ of water was instilled into the loop, which was returned to the abdomen for two hours to allow adequate time for binding of the toxin to the mucosa. The loop was then rinsed with perfusate and prepared for perfusion as previously described.

Cholera toxin was obtained from Sigma Chemical Company (No C3012).

A very low $(1.6 \mathrm{mmol} / \mathrm{l})$ glucose concentration was used as an additional marker, because luminal disappearance will reflect active transport or mucosal metabolism, or both, and thus viability of mucosa. ${ }^{6}$ It was assumed that any effect of prolonged anaesthesia on the absorption would be similar to all four groups.

\section{LUMINAL PROSTAGLANDIN ASSAY}

One $\mathrm{ml}$ of each collection of good recovery from non-stimulated jejunal perfusions was reserved at $-20^{\circ} \mathrm{C}$ after centrifugation at $2500 \mathrm{rpm}$ for 10 minutes, extracted as described by Powell, ${ }^{8}$ and assayed for prostaglandin $E_{2}$ and $F_{2 \alpha}$ using prostaglandin radioimmunoassay kit (Seragen Inc, Boston) within three weeks. For each prostaglandin a standard curve of percentage binding $v$ pg prostaglandin was plotted using several standards. The amount of $\mathrm{PGE}_{2}$ and $\mathrm{PGF}_{2 \alpha}$ contained in each sample was then calculated using the appropriate curve and corrected for $100 \%$ recovery. Each assay included nonspecific binding standards - that is, no added antibody - and controls. The results were corrected for the flow rate and the wet weight of the perfused segment and expressed in $\mathrm{pg} / \mathrm{ml}$ per min per $\mathrm{g}$ wet weight.

The cross reactivity of $\mathrm{PGE}_{2}$ with $\mathrm{PGF}_{2 \alpha}$ is only $0 \cdot 3 \%$ and $\mathrm{PGF}_{2 \alpha}$ with $\mathrm{PGE}_{2} 1 \cdot 3 \%$. The 
TABLE IV Dietary fat and ion transport

\begin{tabular}{|c|c|c|c|c|c|}
\hline & Water $(\mu l / g$ per min $)$ & $\mathrm{Na}(\mu \mathrm{mol} / \mathrm{g}$ per min $)$ & $C l(\mu$ mollg per min $)$ & $K(\mu \mathrm{mol} / \mathrm{g}$ per min $)$ & Glucose ( $\mu \mathrm{mol} / \mathrm{g}$ per min $)$ \\
\hline $\begin{array}{l}\text { Control }(n=8) \\
\text { Olive oil (HMU) }(n=8) \\
\text { Butter }(H S)(n=6) \\
\text { Corn oil }(\text { HPU })(n=6)\end{array}$ & $\begin{array}{l}+7.67(1.4) \\
+6.99(2.7) \mathrm{NS} \\
-4.78(5 \cdot 0)^{\star \star} \\
+12.9(2 \cdot 0)^{\star}\end{array}$ & $\begin{array}{l}+1.93(0.245) \\
+1.7(0.34) \mathrm{NS} \\
-0.163(0.86) \star \star \\
+2.57(0.285) \mathrm{NS}\end{array}$ & $\begin{array}{l}+0.452(0.173) \\
+0.32(0.49) \mathrm{NS} \\
-0.818(0.56){ }^{\star \star} \\
+0.75(0.35) \mathrm{NS}\end{array}$ & $\begin{array}{l}-0.0456(0.006) \\
-0.11(0.036) \mathrm{NS} \\
-0.213(0.102) \mathrm{NS} \\
-0.067(0.016) \mathrm{NS}\end{array}$ & $\begin{array}{l}+0.179(0.011) \\
+0.184(0.02) \mathrm{NS} \\
+0.147(0.03) \mathrm{NS} \\
+0.156(0.014) \mathrm{NS}\end{array}$ \\
\hline
\end{tabular}

Values are expressed as mean (SEM). Values $v$ control: ${ }^{\star} \mathrm{p}<0.05 ;{ }^{\star \star} \mathrm{p}<0.025 . \mathrm{NS}=$ not significant.

recovery of total counts is better than $95 \%$. The coefficient of variation of $\mathrm{PGE}_{2}$ is $8.5 \%$ (intraassay) and $5 \cdot 0 \%$ (interassay) and for $\mathrm{PGF}_{2 \alpha} 8 \cdot 1 \%$ (intra-assay) and $5 \cdot 0 \%$ (interassay).

Rats were sacrificed at the end of the experiment by cardiac puncture and the perfused segment removed and weighed after stripping fluid from the lumen. In all the experiments the concentration of glucose in the effluent was checked by a specific glucose oxidase method (Beckman glucose analyser), $\mathrm{Na}^{+}$and $\mathrm{K}^{+}$by ion selective electrode (Beckman ASTRA), and $\mathrm{Cl}^{-}$ by the colorimetric titration technique (Corning 920). ${ }^{14} \mathrm{C}$-polyethylene glycol activity in $100 \mu \mathrm{l}$ aliquots (in duplicate) were counted in Scintranfluoran $\mathrm{HV}(\mathrm{BDH})$ in a Beckman scintillation counter. Only 100 (5)\% of ${ }^{14} \mathrm{C}$ PEG levels were accepted as good recovery.

\section{STATISTICAL ANALYSIS OF THE RESULTS}

One way analysis of variance (Anova) and unpaired Student's $t$ test were used to analyse the statistical significance of the differences between the means of water and electrolyte absorption. The values obtained were reported as mean (SEM).

The non-parametric Kruskal-Wallis test of variance and Mann-Whitney $U$ test were used to analyse the statistical significance of the differences of prostaglandin concentration between the groups. The values obtained were reported as mean (SEM) and range.

\section{Results}

\section{CHARACTERISTICS OF ANIMALS}

The weight of animals at the beginning and at the end of the experiments and the duration of feeding did not significantly differ between the four groups (Table III). No change in the frequency or in the consistency of stool was observed during the feeding period.

EFFECTS ON JEJUNAL ION TRANSPORT

Feeding rats corn oil enhanced the absorption of water $(\mathrm{p}<0.05 v$ control; $\mathrm{p}<0.005 v$ olive oil and

TABLE V Effects of dietary fat on luminal prostaglandins $(P G)$

\begin{tabular}{lll}
\hline & \multicolumn{2}{l}{$p g / m l$ per min per $g$ wet weight of perfused segment } \\
\cline { 2 - 3 } Diet (no of perfusions) & $P G E_{2}$ & $P G F_{2 u}$ \\
\hline Control $(\mathrm{n}=8)$ & $24 \cdot 1(3 \cdot 6)(5 \cdot 9-33 \cdot 4)$ & $2 \cdot 9(0 \cdot 9)(0 \cdot 5-5 \cdot 4)$ \\
Butter (HS) $(\mathrm{n}=6)$ & $23 \cdot 7(3 \cdot 0)(11 \cdot 8-33 \cdot 2)$ & $2 \cdot 9(1 \cdot 3)(0 \cdot 2-11 \cdot 03)$ \\
Olive oil (HMU) $(\mathrm{n}=8)$ & $37 \cdot 04(4 \cdot 3)(21 \cdot 6-52 \cdot 1)^{\star}$ & $7 \cdot 4(1 \cdot 7)(1 \cdot 9-14 \cdot 7)^{\star \star}$ \\
Corn oil (HPU) $(\mathrm{n}=6)$ & $17 \cdot 9(2 \cdot 4)(9 \cdot 1-26 \cdot 2)$ & $2 \cdot 37(0 \cdot 4)(0 \cdot 3-4 \cdot 03)$ \\
\hline
\end{tabular}

Values are expressed as mean (SEM) and range. the synthetic diets (Table I). butter $), \mathrm{Na}^{+}(\mathrm{p}<0.05 v$ olive oil; $\mathrm{p}<0.005 v$ butter), and $\mathrm{Cl}^{-}(\mathrm{p}<0.025 v$ butter only), but did not significantly change the absorption of $\mathrm{K}^{+}$or glucose.

Feeding butter fat reduced the absorption of water, $\mathrm{Na}^{+}$, and $\mathrm{Cl}^{-}(\mathrm{p}<0.025 v$ control) without significantly changing the absorption of $\mathrm{K}^{+}$and glucose (Table IV). Olive oil did not significantly alter the transport of water or electrolyte during perfusion studies.

\section{EFFECTS ON LUMINAL EICOSANOIDS}

Feeding rats either butter or corn oil did not significantly change the luminal $\mathrm{PGE}_{2}$ and $\mathrm{PGF}_{2 \alpha}$ during in vivo steady state perfusion studies as compared to low fat chow diet.

Feeding rats olive oil increased the production of luminal $\mathrm{PGE}_{2}$ ( $\mathrm{p}<0.005 v$ control; $\mathrm{p}<0.025 v$ butter and corn oil) and also increased the production of luminal $\mathrm{PGF}_{2 \alpha}(\mathrm{p}<0.025 v$ control and butter; $\mathrm{p}<0.005 v$ corn oil). Comparing the effects of dietary fat on the mean $\mathrm{PGE}_{2} / \mathrm{PGF}_{2 u}$ ratio, it seems that feeding rats olive oil increased both prostaglandins, particularly PGF $_{2 \alpha}$, whereas feeding corn oil appreciably decreased $\mathrm{PGE}_{2}$ compared to the low fat diet (Table V).

EFFECTS ON CHOLERA TOXIN-INDUCED SECRETION Feeding rats high dietary fat did not significantly alter the absorption of glucose at the low concentration used. High monounsaturated and high polyunsaturated dietary fat, compared with low fat intakes, reduced the effects of cholera toxin on secretion of water and electrolytes (Figs 1 and 2).

Taking into consideration the baseline absorption of unstimulated jejunum, it seems that all three high dietary fat regimens reduced the net secretory response to cholera toxin by about $50 \%$.

\section{Discussion}

The absorption values of these perfusion studies were lower than those previously reported. ${ }^{710}$ The reason behind these variations may be related to the variation in the $\mathrm{Na}^{+}$content of the perfusate, the relatively higher osmolality, lower glucose, lower total $\mathrm{CO}_{2}$, and lower flow rate in this study, the variation in the ages of the animals, and the units used to express the data. Since our aim was to compare the effects of different dietary fat on ion transport under the same conditions, however, the comparisons are valid. ${ }^{11}$

Prostaglandin synthesis in the intestine occurs predominantly in the subepithelial cells, whereas the capacity to degrade prostaglandins lies mainly in the epithelial cells. ${ }^{12}$ Prostaglandins are not stored in tissue but are continually formed and 


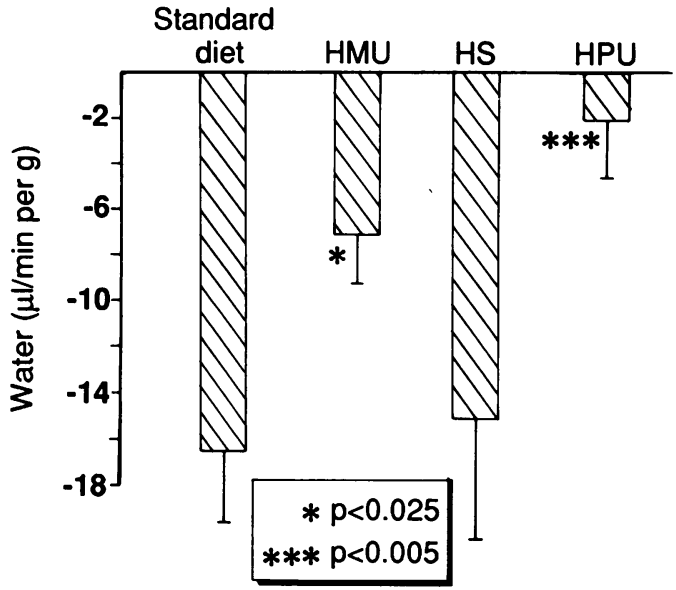

Figure 1: Secretory (water) response of jejunum to cholera toxin in rats fed diets with differing fatty acid contents. $H M U=$ high monounsaturated (olive oil); $H S=$ high saturated (butter); HPU = high polyunsaturated (corn oil) Values are shown as mean (SEM)). The number of perfusions were 10 each for the control and corn oil groups and eight each for the olive oil and butter groups. p values are between control (standard diet) and other groups.

released. Determination of luminal $\mathrm{PGE}_{2}$ concentrations provides a simple and reproducible index of intestinal prostaglandin production which may be used for studies of pathophysiological mechanisms. ${ }^{13}$ The use of a valid marker perfusion technique may provide a reliable index of local prostaglandin synthesis after exclusion of the luminal fluids from the stomach, pancreas, and bile.

The sequence of biochemical events that occurs between ingestion of dietary fat and tissue prostaglandin production is complex, with several steps of autoregulation, and the effects of dietary manipulation on prostaglandin synthesis in various body organs are difficult to predict.

Permeability properties of the lipid bilayer are greatly dependent on the nature and chain length of the fatty acid constituents of lipid molecules. ${ }^{14}$ High dietary polyunsaturated fat is known to increase the fluidity of the enterocyte plasma membrane, ${ }^{15}$ which in turn produces a more permeable membrane due to reduced attractive forces between adjacent lipid molecules. ${ }^{16} 17$ The observations that high polyunsaturated fat appreciably increased the activity of $\mathrm{Na}^{+} / \mathrm{K}^{+}$ ATPase in the basolateral membranes, ${ }^{15}$ significantly increased tissue concentration of somato-

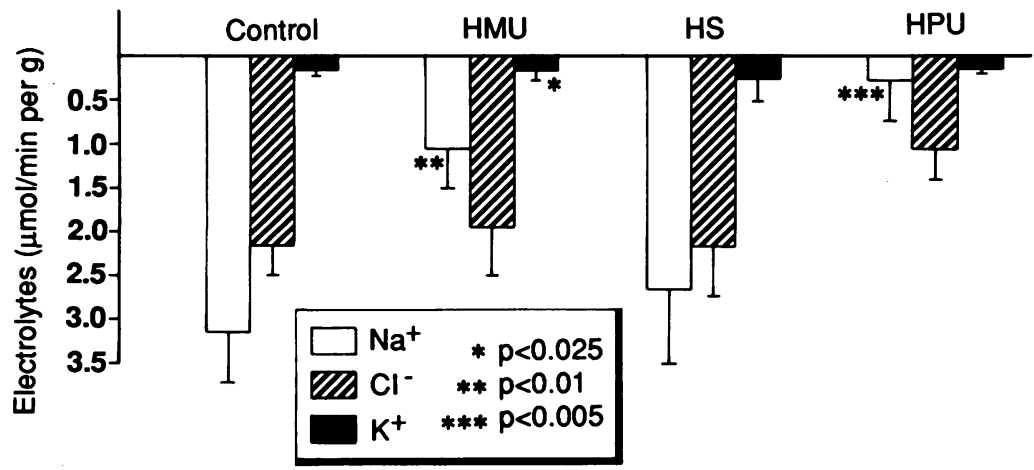

Figure 2: Secretory (electrolyte) response of jejunum to cholera toxin in rats fed diets with differing fatty acid contents. HMU = high monounsaturated (olive oil); HS = high saturated (butter); HPU=high polyunsaturated (corn oil). Values are shown as mean (SEM)). The number of perfusions were 10 each for the control and corn oil groups and eight each for the olive oil and butter groups. p values are between control (standard diet) and other groups. statin in the proximal small intestine (submitted data), ${ }^{18}$ and appreciably increased villous heights in the jejunum (submitted data) ${ }^{18}$ might lead to an expectation of enhanced absorption. ${ }^{19}$ The alterations in prostaglandins produced by diet may be relevant, since luminal $\mathrm{PGE}_{2}$ in rats fed corn oil was reduced to lower levels than in the control groups ${ }^{20}$ (Table V). Polyunsaturated fat may therefore inhibit a prostaglandin mediated step in intestinal secretion beyond the generation of cAMP. ${ }^{21}$

In contrast, rats on high monounsaturated dietary fat showed no significant alteration in ion transport compared with low fat control groups. Their luminal $\mathrm{PGE}_{2}$ and $\mathrm{PGF}_{2 \alpha}$ were significantly increased during perfusion (Table $\mathrm{V}$ ), however, and the fact that an increase in luminal $\mathrm{PGE}_{2}$ has been shown to increase the inhibition of $\mathrm{Na}^{+} / \mathrm{K}^{+}$ATPase and stimulate adenyl cyclase ${ }^{21}$ may explain the relative reduction in the absorption of water and electrolyte compared with the corn oil group.

High saturated fat reduces the permeability of the enterocyte plasma membrane, ${ }^{16}{ }^{17}$ greatly reduces $\mathrm{Na}^{+} / \mathrm{K}^{+}$ATPase activities, ${ }^{15}$ and also reduces the jejunal villus height. ${ }^{18}$ It also increases total phospholipids in intestinal microvillus membranes and in particular membrane bound phosphatidylinositol, ${ }^{15}$ the hydrolysis of which is accompanied by more gating of $\mathrm{Ca}^{2+}$ across the basolateral membrane. This calciumgating process increases ionised $\mathrm{Ca}^{2+}$ levels in the cell and this is thought to stimulate secretion through $\mathrm{Ca}^{2+}$ dependent protein kinases. This is under investigation in our laboratory. These factors in combination may explain the appreciable reduction in water and electrolyte transport that we observed in the high saturated fat group (Table IV).

We used a single, very low glucose concentration as a marker to show the viability of the mucosa. Further studies using different concentrations of glucose are required to elucidate the possible effects of fat on glucose absorption. Previous in vitro studies showed that the rate of jejunal uptake of D-glucose varied from $0 \cdot 5-20$ mmol and was higher in animals fed high polyunsaturated fat. ${ }^{22}$

Cholera toxin-induced stimulation serves as a useful model of secretory diarrhoea in experimental studies. Cholera toxin is a protein molecule, which consists of a B subunit containing five non-covalently linked molecules and an A subunit containing two peptides, $A_{1}$ and $A_{2}$, linked by a disulphide bond. ${ }^{23}$ In a comprehensive review of the pathogenesis of cholera, Hendrix ${ }^{24}$ concluded that there is no evidence that cholera toxin increases epithelial permeability or osmotic or hydrostatic gradients, and the increased intestinal fluid secretion stimulated by cholera toxin arises from increased filtration through normal calibre 'channels.' The gross effect of cholera toxin is the production of water and electrolyte secretion by a complex biochemical mechanism, not yet well understood. It involves a rise in cAMP, which causes active secretion of $\mathrm{Cl}^{-}$from the crypts and inhibits active electrogenic $\mathrm{Na}^{+}$-coupled glucose absorption. ${ }^{25}$ It is not definitely known how the binding of the B subunit to a specific membrane glyco- 
lipid mediates the entry of the A subunit or whether this is the only mechanism by which cholera toxin induces a secretory state.

In the present studies, if we can extrapolate from baseline studies in male rats to the cholera toxin-induced studies in female animals, it seems that the pre-existing absorptive/secretory state of the mucosa has a pronounced effect on the secretory response to toxin. Thus, bearing in mind that a butter diet produced a small net secretory state when unstimulated whereas corn oil apparently enhanced water and electrolyte absorption, all three fat supplements reduced the net secretory response by about half. This suggests that the fundamental mechanism by which cholera toxin activates secretion is unchanged, although a number of other theories may explain variations in both the unstimulated absorption and the toxin response.

The changes in membrane composition induced by dietary fat may determine the binding of bacteria or toxin to the intestinal cells. Studies on animals have shown that more cholera toxin binds to the microvillus membrane of the newborn rabbit compared with adults ${ }^{26}$ and these effects may be related to the reduced ratio of protein/phospholipids commonly found in the immature membrane of the newborn. ${ }^{27} 28$

Although high polyunsaturated dietary fat reduces the total phospholipids in microvilli, ${ }^{29}$ which may in turn reduce the binding sites available for cholera toxin, this is unlikely to be the only explanation for our observations. Polyunsaturated fat, however, can increase activity of $\mathrm{Na}^{+} / \mathrm{K}^{+}$ATPase in the basolateral membrane, ${ }^{1530}$ and this could counteract the secretory effect of adenyl cyclase induced by cholera toxin.

The $\mathrm{Na}^{+}$-coupled glucose absorption route is unlikely to be involved in the protective mechanism of unsaturated dietary fat because cholera toxin does not interfere with $\mathrm{Na}^{+}$-coupled glucose transport ${ }^{25}$ and dietary fat did not appreciably alter the absorption of glucose at the low concentration used in this study.

Polyunsaturated fat significantly increased the tissue concentration of somatostatin in the proximal segment of rat small intestine compared to the low fat group (submitted data)..$^{18}$ Somatostatin inhibits in vivo jejunal secretion induced by $\mathrm{PGE}_{1}$ and theophylline in rats, ${ }^{31}$ improves diarrhoea in human carcinoid syndrome ${ }^{32}$ and in severe refractory secretory diarrhoea, ${ }^{33}$ and inhibits adrenergic and cholinergic neurotransmission in smooth muscle. ${ }^{34}$ High tissue concentrations of somatostatin may therefore contribute to the protective effects of corn oil in secretory diarrhoea.

The protective mechanism of olive oil may involve different mediators. Rats maintained on high monounsaturated dietary fat (olive oil) had high levels of luminal $\mathrm{PGE}_{2}$ and $\mathrm{PGF}_{2 \alpha}$ during unstimulated perfusion studies. This might be expected to alter the interdigestive motility pattern of the small intestine $e^{35}$ and contribute to sodium and chloride secretion. ${ }^{3637}$

The possibility exists that stimulation of adenyl cyclase by prostaglandin $s^{36}$ and by cholera toxin $^{25}$ is through different and antagonistic or competitive pathways.
The applicability of these studies to diarrhoeal disorders in humans is not known, but preliminary clinical observations suggest that the fatty acid composition of cell membranes may be related to the varying severity of childhood diarrhoea in different populations. ${ }^{38}$

We thank Mr T McFarlane, Royal Belfast Hospital for Sick Children, and Mr T Oliver, Department of Food Biochemistry, Faculty of Agriculture, Queen's University of Belfast, for their technical help.

1 Koopman JS, Turkisk VJ, Monto AS, Thompson FE, Isaacson RE. Milk fat and gastrointestinal illness. $A m \mathcal{F}$ Public Health 1984; 74: 1371-3.

2 Cohen SA, Kirsty M, Hendricks KM, Eastham EJ, Mathis RK, Walker WA. Chronic non-specific diarrhea: a complication of dietary fat restriction. Am $\mathcal{F}$ Dis Child 1979; 133: $490-2$

3 Cohen SA, Hendricks KM, Mathis RK, Laramee S, Walker WA. Chronic non-specific diarrhea - dietary relationships. Pediatr Res 1979; 64: 402-7.

4 Otnaess AB, Svennerholm AM. Non-immunoglobulin fraction of human milk protects rabbits against enterotoxinfraction of human milk protects rabbits against enterotoxin-
induced intestinal fluid secretion. Infect Immun 1982; 35: induced

5 Ashkenazi S, Mirelman D. Non-immunoglobulin fraction of human milk inhibits the adherence of certain enterotoxogenic Escherichia coli strains to guinea pig intestinal tract. Pediatr Res 1987; 22: 130-4

6 Sandhu BK, Tripp JH, Candy DCA, Harries JT. Loperamide studies on its mechanism of action. Gut 1981; 22: 658-62.

7 Sladen GE, Harries JT. Studies on the effects of unconjugated dihydroxy bile salts on rat small intestinal function in vivo. Biochim Biophys Acta 1972; 288: 443-56.

8 Powell WS. Rapid extraction of oxygenated metabolites of arachidonic acid from biological samples using octadecylsilyl silica. Prostaglandins 1980; 20: 947-57.

9 Harries JT, Sladen GE. The effect of different bile salts on the absorption of fluid, electrolytes and mono-saccharides in the absorption of fluid, electrolytes and mono-saccharides in
small intestine of the rat in vivo. Gut 1972;13: 596-603.

10 Powell DW, Malawer SJ. Relationship between water and solute transport from is-osmotic solutions by rat intestine in vivo. F Physiol 1986; 215: 49-55

11 Ewe $K$, Wanitschke R, Staritz $M$. Intestinal permeability studies in humans. In: Csaky TZ, ed. Handbook of experimental pharmacology. Vol 70. Intestinal permeation part II Berlin: Springer Verlag, 1984: 535-71.

12 Smith SG, Worhurst G, Turnberg LA. Synthesis and degradation of $\mathrm{PGE}_{2}$ in the epithelial and subepithelial layers of the rat intestine. Biochim Biophys Acta 1982; 713: 684-7.

13 Bukhave K, Rask-Madsen J. Prostaglandin $\mathrm{E}_{2}$ in jejunal fluids and its potential diagnostic value for selecting patients with indomethacin-sensitive diarrhoea. Eur $\mathcal{F}$ Clin Invest 1981; 11: $191-7$.

14 Jain MK, Wagner RC. Introduction to biological membranes. New York: John Wiley, 1980: 117-42.

15 Brasitus TA, Davidson NO, Schachter D. Variation in dietary triglycerol saturation alters the lipid composition and fluidity of rat intestinal plasma membranes. Biochim Biophys Acta 1985; 812: 460-72.

16 Boggs JM. Intermolecular hydrogen bonding between lipids influence on organization and function of lipids in membranes. Can F Biochem 1980; 58: 755-70.

17 Chapman D. Phase transitions and fluidity characteristics of lipids and cell membranes. $O$ Rev Biophys 1975; 8: 185-235.

18 Sagher FA. The effect of variation in dietary fat in early life, with particular reference to the small intestine. $\mathrm{PhD}$ Thesis: with particular reference to the small inte
1988. The Queen's University of Belfast.

19 Riecken EO, Lorenz-Meyer M, Sahfeld M, Bloch R. Relationship between structure and function in the human intestine. In: Robinson JWL, ed. Intestinal ion transport. London: In: Robinson JWL, ed.

20 Sagher FA, Dodge JA, Moore R. Modification of rat jejunal ion transport and luminal eicosanoids by dietary fat [Abstract]. Gut 1988; 29: A1439.

21 Rachmilewitz D, Karmeli F, Okon E. Effects of bisacodyl on cAMP and prostaglandin $\mathrm{E}_{2}$ content, $\mathrm{Na}^{\prime}-\mathrm{K}^{\prime}$ ATPase, adenyl cyclase and phosphodiesterase activities of ra intestine. Dig Dis Sci 1980; 25: 602-8.

22 Thomson ABR, Keelan M, Clandinin MT, Walker K. Dietary fat selectively alters transport properties of rat jejunum. f Clin Invest 1986; 77: 279-88.

23 Kurosky A, Markel DE, Touchstone B, Peterson W. Chemical characterization of the structure of cholera toxin Chemical characterization of the structure of cholera
and its natural toxoid. $\mathcal{F}$ Infect Dis $1975 ; 133$ : 514-22.

and its natural toxoid. F Infect Dis 1975; 133: 514-22.
24 Hendrix TR. Effect of cholera enterotoxin on intestinal pendrix TR. Effect of cholera enterotoxin on intestinal
permeability. In: Csaky TZ, ed. Handbook of experimental permeability. In: Csaky TZ, ed. Handbook of experimental
pharmacology. Vol 70. Intestinal permeation part II. Berlin: pharmacology. Vol 70. Intestinal

25 Serebro HA, Bayless TM, Hendrix TR, Iber FL, McGonagle $\mathrm{T}$. Absorption of $\mathrm{D}$ glucose by rabbit jejunum during cholera induced diarrhoea. Nature 1968; 217: 1272-3.

26 Bresson JL, Pang K, Udall J, Fritze L, Walker WA. Evidence for increased enterotoxin binding to newborn microvillous membranes: a possible explanation for enhanced toxigenic diarrhoea in infancy [Abstract]. Gastroenterology 1980; 78: A1145.

27 Chu S W, Walker WA. Development of the gastrointestinal mucosal barrier: changes in phospholipid head groups and 
fatty acid composition of intestinal microvillous membrane from newborn and adult rats. Pediatr Res 1988; 23 439-42.

28 Bresson JL, Pang K, Walker WA. Microvillous membrane differentiation: quantitative difference in cholera toxin binding to the intestinal surface of newborn and adult rabbit. Pediatr Res 1984; 18: 984-7.

29 Brasitus TA, Davidson NO, Schachter D. Variations in dietary triglycerol saturation alter the lipid composition and fluidity of rat intestinal plasma membranes. Biochim Biophys Acta 1985; 812: 460-72.

30 Charney AN, Gots RE, Giannella RA. $\left(\mathrm{Na}^{+}-\mathrm{K}^{+}\right)$-stimulated adenosinetriphosphatase in isolated intestinal villous tip and crypt cells. Biochim Biophys Acta 1974; 367: 265-70.

31 Dharmsathaphorn K, Sherwin RS, Dobbis JW. Somatostatin inhibits fluid secretion in rat jejunum. Gastroenterology 1980;

32 Davis GR, Camp RC, Krejs GJ. Effect of somatostatin infusion on jejunal water and electrolyte transport in a patient with carcinoid syndrome and in healthy subjects [Abstract]. Gastroenterology 1979; 76: A117.
33 Jaros W, Biller J, Greer S, O'Dovisio T, Grand R. Successful treatment of idiopathic secretory diarrhea of infancy with the somatostatin analogue SMS 201-995. Gastroenterology 1988

34 Cohen JL, Rosing E, Wiley KS, Slater IH. Somatostatin inhibits adrenergic and cholinergic neurotransmissions in smooth muscle. Life Sci 1978; 23: 1659-64.

35 Tollstrom T, Hellstorm PM, Johansson C, Pernow B. Effects of prostaglandins $E_{2}$ and $F_{2 u}$ on motility of small intestine in man. Dig Dis Sci 1988; 33: 552-7.

36 Rachmilewitz D, Karmeli F, Okon E. Effects of bisacodyl on cAMP and prostaglandin $\mathrm{E}_{2}$ content, $\mathrm{Na}^{\prime}-\mathrm{K}^{\prime}$. ATPase, adenyl cyclase and phosphodiesterase activities of rat intestine. Dig Dis Sci 1980; 25: 602-8.

37 Mozsik G, Kutas J, Nagy L, Nemeth G. Inhibition of $M^{\prime 2}-\mathrm{Na}^{\prime}-\mathrm{K}$ dependent ATPase systems from human gastric

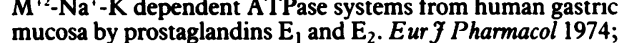
29: 133-7

38 McClean P, Sagher FA, Akhtar T, Dodge JA. Does dietary fat affect the severity of childhood diarrhea? [Abstract]. Pediatr Res 1989; 26: 268. 